\title{
Modernidad y postmodernidad en Latinoamérica
}

\author{
José G. Vargas Hernández \\ Profesor investigador miembro del Sistema Nacional de Investigadores \\ Instituto Tecnológico de Cd. Guzmán (México)
}

Recibido: 30.12 .06

Aceptado: 07.05 .07

\begin{abstract}
Resumen: En este trabajo se revisan los principales desarrollos del capitalismo en Latinoamérica caracterizados como tiempos premodernos, modernos y postmodernos que ponen en una encrucijada al desarrollo económico y social de la región. Se revisan los conceptos de modernidad como un enfoque teórico del desarrollo económico y de postmodernidad como una tendencia de pensamiento del desarrollo del capitalismo tardío o postindustrial aunado a los procesos de globalización, para delimitar el final de la modernidad organizada. Se concluye que los procesos contemporáneos de la globalización y la expansión del capitalismo tardío o postmoderno han agravado los más crónicos problemas del desarrollo económico y social como en la región latinoamericana.
\end{abstract}

Palabras clave: Latinoamérica, modernidad, postmodernidad.

Abstract: This paper reviews the main progresses of capitalism in Latin America, categorized as premodern, modern and postmodern times, which set the economic and social development of the region at the crossroads. The concepts of modernity as a theoretical approach to economic development and that of postmodernity as a current of thought of late or postindustrial capitalist development, together with the globalization processes, are reviewed in order to draw up the boundaries of the end of organized modernity. It is concluded that the contemporary processes of globalization and the expansion of late and postmodern capitalism have aggravated the chronic problems of economic and social development in the Latin American region.

Key words: Latin America, modernity, postmodernity.

Sumario: I. Modernidad.--II. Teoría de la modernidad.--III. Estrategias de modernización neoliberal y estructuralista.-IV. Postmodernidad.V. Modernidad y procesos de globalización.-VI. El final de la modernidad organizada.-VII. Modernidad y postmodernidad como formas de sustentabilidad social.-VIII. Nuevos movimientos sociales y acción colectiva.IX. La encrucijada de los tiempos premodernos, modernos y postmodernos en Latinoamérica.-X. Conclusiones.-XI. Bibliografía.

\section{Modernidad}

Habermas (1992: 228) puntualiza que el vocablo modernización se introduce como término técnico en los años cincuenta; caracteriza un enfoque 
teorético que hace suyo el problema del funcionalismo sociológico. La modernidad se define como el desarrollo económico industrializado con una convergencia hacia la democracia liberal. La democracia es el espacio donde convergen la igualdad y la libertad que tienen como condición necesaria, aunque no suficiente, la participación efectiva en los aspectos procedimentales para la elaboración del sistema normativo.

El concepto de modernización se refiere a una gavilla de procesos acumulativos que se refuerzan mutuamente: a la formación de capital y a la movilización de recursos; al desarrollo de las fuerzas productivas y el incremento de la productividad del trabajo; a la implantación de poderes políticos centralizados y al desarrollo de identidades nacionales; a la difusión de los derechos de participación política, de las formas de vida urbana y de la educación formal; a la secularización de los valores y normas; etc.

Los conceptos de democracia relacionada con la noción de capitalismo, coinciden con la definición de modernidad, con implicaciones que datan de la Ilustración y que todavía no alcanzan su máximo potencial de desarrollo. La democracia es el espacio donde convergen la igualdad y la libertad que tienen como condición necesaria aunque no suficiente, la participación efectiva en los aspectos procedimentales para la elaboración del sistema normativo. El proceso político se desarrolla en las etapas de diseño de normas y de desarrollo del juego político.

Con la modernidad se desarrolla un proceso de desculturalización que libera a los individuos de las relaciones sociales feudales y patriarcales, dando lugar a nuevas culturas democráticas. La desculturalización agredió a identidades culturales, las cuales resisten y se reinvindican hasta nuestros tiempos mediante procesos de reterritorialización de los espacios locales en un ambiente de globalización económica imperante. Existen varias culturas democráticas que pueden ser delimitadas a partir de los elementos de la cultura política. La cultura política toma forma específica en cada nación como un producto a largo plazo de la historia. La cultura así llamada conforma un conjunto de modos de vida de las naciones.

Los inicios de la modernidad están marcados por una racionalidad que tuvo como fundamento ideas religiosas, la revelación, la opinión y la autoridad que mezcladas con intereses políticos y cánones en el siglo XVI da lugar a un modelo antropológico que en el siglo XVII deriva en el cálculo con base en las matemáticas y la geometría. La modernidad desenlaza procesos de transformación en Europa desde el siglo XVII, los cuales provocaron rupturas con las relaciones sociales y el orden religioso prevaleciente en el último milenio. Un creciente desarrollo de procesos de racionalización y secularización del conocimiento sustituyen gradualmente los dogmas religiosos por el avance de la ciencia.

Mediante los crecientes procesos de racionalización, el cálculo racional instrumental y frío sustituye a los dogmas de una fe religiosa. La modernidad libera a los grupos humanos de una visión religiosa del mundo que 
somete las relaciones sociales a estrictos comportamientos dogmáticos. La deficiencia de la racionalidad tiene precedentes en el trabajo teológico del siglo XVI y en el empirismo de Bacon a principios del siglo XVII que anuncia su fe en el progreso. Una pugna cultural se ha descollado entre las tradiciones filosóficas europeas y las actitudes científicas y tecnológicas que se gestan en la potencia económica estadounidense. El racionalismo ateo de la Ilustración no tocó las sectas de Nueva Inglaterra por lo que su cultura se mantuvo cerca de las brujas de Salem.

La Ilustración fue una tendencia que acompañó a la modernidad en un trayecto. La filosofía de la Ilustración sirvió de base para la creación de las culturas e ideologías europeas modernas que influyeron en la formación de los primeros centros del desarrollo capitalista, ya fueran católicos (Francia) o protestantes (Inglaterra y Holanda), y también en Alemania y Rusia; su impacto alcanza hasta nuestra época.

El Romanticismo alemán exaltó el nacionalismo y lo opuso al cosmopolitismo que sujeta a los Estados al derecho internacional cosmopolítico (Kant) que postula que todos los pueblos están originariamente en comunidad del suelo sin la posesión jurídica, concepto que choca con el de soberanía, que postula a la nación como propietaria de un territorio determinado y al Estado como su representante. Para Kant, la nación es una persona moral cuyo origen es un contrato social, una comunidad que, vinculada por la fraternidad, busca alcanzar el bien común y la paz. En el Contrato Social de Rousseau se afirma la necesidad de hallar una forma de asociación por la que cada cual, uniéndose a todos, no obedezca, sin embargo, más que a sí mismo.

En el siglo XVII las Provincias Unidas de Holanda promovían el libre comercio de su producción en los países europeos, pero protegían ciertos mercados en los que eran débiles. Los británicos sostuvieron tres guerras contra los holandeses para disputarse el mercado mundial. Al decir del británico George Downing en 1663, la política comercial holandesa es un mar abierto (mare liberum) en las aguas británicas, pero un mar cerrado (mare clausum) en la costa de África y las Indias Occidentales.

En el siglo XVIII aparece una orientación objetiva del hombre para considerarlo moralmente como valor supremo. Algunas de las ciencias sociales positivizan al hombre convirtiéndolo en objeto, mientras que las filosofías subjetivas imponen la noción que el hombre se hace a sí mismo. La cultura occidental tiene como característica principal el humanismo que tiende a ser un espejismo cuando se comunica con los valores humanistas de otras culturas. Así, la fe se ha ajustado para cumplir con los requisitos de los valores de la modernidad, el laicismo y la democracia.

El desarrollo de Inglaterra se sustentó en las tesis del liberalismo económico y la economía política clásica elaborada por los ingleses Adam Smith, Thomas R. Malthus, David Ricardo y el francés Jean Baptiste Say, basada en el ahorro, el trabajo y el libre comercio. Por otro lado, los trabajos de David 
Ricardo sobre las ventajas comparativas y su interpretación moderna en el modelo Heckscher-Ohlin de comercio internacional establecen que las diferencias en las ventajas comparativas de las naciones en la producción de diferentes mercancías se deben a las diferentes dotaciones de factores. En el capitalismo, la producción adquiere más importancia que la distribución y el consumo porque implica la propiedad de los recursos económicos, principal fuente del poder económico, no obstante que el comercio internacional contribuye a crear la plusvalía.

Pero la aplicación de estas tesis son contradictorias e incompatibles con «el empleo sistemático del poder político, militar y económico del país en una praxis de colonialismo, proteccionismo y explotación de los pueblos bárbaros» (Dietererich, 2002:8). Friedrich List, formador del capitalismo del Estado Alemán a finales del siglo XVIII y principios del XIX, critica esta doble moral inglesa, la cual se sintetiza en el análisis de Dietererich (2002:9) porque desde «la constitución del moderno estado inglés en la dictadura desarrollista de Oliver Cromwell tal como se había manifestado en el Acta de Navegación (1651) y el monopolio de la East India Company, hasta los días del encantador Tony Blair, la única política real de crecimiento económico ha sido el capitalismo proteccionista de Estado».

El surgimiento del capitalismo concurrente con el fenómeno de la modernidad separa lo político de lo económico. Leviatán es el paradigma moderno de la política instituida en la regulación y resolución de conflictos bajo principios de un orden establecido en un marco normativo. Hobbes mantiene la idea de que la política ligada a un orden natural es contingente, particular, finita y, por lo tanto, incapaz de evadir el retorno al estado de conflicto. La solución Hobbesiana justifica al Dictador que exigirá el resultado que maximiza el bienestar colectivo.

La institucionalización del Estado fue consecuencia de la regulación de las relaciones, el establecimiento de los deberes y obligaciones, así como de la resolución de conflictos de los individuos en la sociedad. El desarrollo supera el enfoque de provisión de bienes y competencias individuales y se orienta a los procesos de institucionalización que garanticen el ejercicio de la conducta de elección de elementos que van más allá de la simple búsqueda y satisfacción del bienestar.

No obstante, la modernidad es la ideología del sistema capitalista que se declara a sí misma como la defensora de los derechos individuales sobre los derechos de la sociedad. La exaltación del individualismo es una característica de los procesos de modernización capitalista que tiene implicaciones en las propuestas de las instituciones democráticas, la familia, etc.

Marx, en su Manifiesto Comunista es sensible al sufrimiento infligido por la modernidad a los esbatimentos sociales burgueses cuando sostiene que la modernidad ha destruido las relaciones feudales, patriarcales, idílicas. Las abigarradas ligaduras feudales que ataban al hombre a sus superiores naturales se han desgarrado sin piedad, para no dejar subsistir otro vínculo entre los 
hombres que el frío interés, el cruel pago al contado. Ha ahogado el sagrado éxtasis del fervor religioso, el entusiasmo caballeresco, y el sentimentalismo del pequeño burgués en las aguas heladas del cálculo egoísta. Ha hecho de la dignidad personal un simple valor de cambio. Ha sustituido las numerosas libertades escrituradas y adquiridas por la única y desalmada libertad de comercio. En una palabra, en lugar de la explotación velada por ilusiones religiosas y políticas, ha establecido una explotación abierta, descarada, directa y brutal.

Frente a la concepción socialista moderna que ve un problema en la propiedad privada y prefiere una propiedad colectiva, Aristóteles consideraba, en efecto, que solamente lo que el individuo tenía como propio es aquello de que se ocupa con más esmero. Aristóteles pensaría que estaba en la esencia humana el ocuparse más de lo propio que de lo común. Aristóteles no sólo se preocupa por la defensa de la propiedad privada, sino la promoción, al mismo tiempo, de un uso en común. En esto difiere Aristóteles radicalmente de lo que se advierte en el capitalismo de mercado, con su mano oculta que todo lo arregla y sus sociedades anónimas. Pues lo que sucede en la sociedad moderna capitalista es que cada uno se ocupa de lo suyo también en el uso y se desentiende del prójimo.

Esta sociedad moderna se organiza en torno al Estado-nación asentado en un territorio donde se realizan las diferentes interacciones, entre las décadas de los treinta y los setenta del siglo pasado Las sociedades modernas tienen como características la diferenciación social, la secularización de la cultura política y un sistema político. El concepto hegeliano de una sociedad civil burguesa adquiere vigor y se involucra en el espacio público en forma de opinión pública en las sociedades modernas. La opinión pública es la característica que diferencia la sociedad civil del Estado y que representa la voz de la sociedad civil en la esfera política. La sociedad civil es una red asociativa que comprende todos los intereses sociales y facilita la participación de los ciudadanos que forman parte de un sistema político. Esta modernidad se declara a favor de los derechos del individuo en franca oposición a los derechos sociales, lo que afirma más la tendencia autoritaria del capitalismo. El pensamiento social burgués separa los dominios económico y político de la vida social (Amín, 2001) mediante la adopción de diferentes principios específicos.

La convergencia de la modernización económica, definida como desarrollo económico industrializado, y la democracia liberal requiere de nuevas instituciones, actores y agentes e involucra limitadamente las capacidades del Estado. Por otro lado, si la dictadura del trabajo domina, la democracia tampoco puede florecer. Al respecto Birchfield (1999) nos recuerda que la relación del salario capitalista necesita la separación conceptual de la economía y la política respectivamente en esferas privadas y públicas de actividad, lo que a su vez constituye un elemento definitorio del Estado liberal. La estrategia de modernización económica seguida por la mayor parte de los 
países del mundo sólo reporta beneficios derivados del manejo de grandes capitales y de los avances tecnológicos para las grandes transnacionales. La tradición ideológica de las elites viejas como estrategia de los grupos de nivel socioeconómico alto se orienta a limitar la modernización económica al mismo tiempo que fortalece los valores tradicionales de socialización centrada en la familia y en la escuela (Germani, 1966).

Sin embargo, no existe necesariamente una relación lineal entre la modernización económica y el establecimiento de instituciones democráticas. Además, el logro de crecimiento económico no es garantía de un desarrollo democrático. Investigaciones sobre la cultura política concluyen que la crisis política tiene poca relación con la crisis de confianza en las instituciones democráticas, cuyo nivel de aceptación sigue siendo elevado. Así, un elevado desarrollo económico puede coexistir con un debilitamiento de las relaciones de confianza y cooperación cívica (Grootaert, 1998). Consolidar la democracia liberal requiere de instituciones, actores y agentes que acepten las reglas del juego y los principios del liberalismo político y económico.

El territorio es un elemento de la modernidad política que es analizado como un constructo social formado por personas, fenómenos y relaciones determinadas en un área geográfica que se afectan e influyen mediante intenciones individuales y grupales. Dentro de esta concepción amplia del territorio aparecen las instituciones que se vinculan y relacionan de formas distintas en el espacio.

Brosius (1997:34) afirma que no es fácil conceptualizar las formas concretas en que se presenta el tráfico en dos sentidos entre lo local y lo global y argumenta que «incluso el componente local de los movimientos sociales en contra de las naturalezas del capital y de la modernidad está de alguna manera globalizado, por ejemplo en la medida en que dichos movimientos sociales toman prestados discursos metropolitanos sobre la identidad y el entorno». Los movimientos contestatarios a la modernidad y a los procesos de globalización resisten la desculturalización bajo una política de identidades y la secularización mediante una reactualización de los fenómenos religiosos.

\section{Teoría de la modernidad}

La teoría de la modernización plantea como hipótesis que el desarrollo económico traerá consigo el desarrollo político. La homogeneidad y estandarización de todas las formas de civilización humana bajo un mismo sistema económico puede tener consecuencias fatales para el desarrollo de la humanidad. El sistema económico capitalista se encuentra atrapado funcionalmente en una lógica de crecimiento económico insostenible. La hipótesis central de la teoría del desarrollo centrado en la modernidad plantea que el 
desarrollo económico traerá consigo el desarrollo político. Las teorías del desarrollo son la basada en monoeconomía y la de beneficios mutuos. Las principales teorías sobre el desarrollo socioeconómico son la teoría de la modernización, la dependencia, la globalización y los sistemas mundiales.

Los vínculos que explican las diferentes relaciones económicas, sociales, políticas, etc., existentes entre las localidades, regiones, países y globalidad se han analizado desde dos enfoques teóricos, el dependencista y el desarrollista. La teoría de la dependencia de la división internacional del trabajo (Cardozo y Faletto, 1969) considera que las diferentes regiones y países tienen intercambios desiguales en un sistema que concentra los recursos tecnológicos, la manufactura, la educación y la riqueza, mientras que otras regiones y países periféricos sólo son proveedores de mano de obra y materia prima barata. Por su parte, la teoría del desarrollo (Lerner, 1958; Rostow, 1960; Germani, 1971) de la división internacional del trabajo considera la importancia de que las denominadas sociedades parciales se modernicen con tecnología y valores tradicionales.

La teoría de la dependencia centra el desarrollo en los mercados domésticos, el papel del sector industrial nacional, generación de demanda agregada mediante incrementos salariales que aumentan los niveles de vida. Las teorías anteriores centran su objeto de estudio en el Estado-nación, a diferencia de las dos siguientes cuyo objeto de estudio toma otras perspectivas. Los procesos de globalización, tal como se están dando hasta ahora, contribuyen a la devaluación de la autoestima de los pueblos ya de por sí subdesarrollados y a crear un sentido de dependencia. La debilitada cultura de la dependencia del pobre es sustituida por el impresionante proyecto hegemónico de expansión del capitalismo alentada por los grandes intereses económicos de los grupos corporativos. La escuela de la dependencia falla al predecir dos importantes tendencias que contradijeron sus expectativas originales: primero, el errático desempeño de los modelos de desarrollo basados en la sustitución de importaciones que intentaron contraatacar la penetración capitalista externa con la intervención vigorosa del Estado y la promoción de industrialización autónoma, y segundo, la experiencia exitosa de algunos de los más dependientes (Portes, 1997).

La teoría de la modernización sostiene que el desarrollo es un proceso sistemático, evolutivo, progresivo, transformador, homogeneizador y de americanización inminente. La teoría de la modernización sostiene que el desarrollo social y político de los pueblos ocurre en el cambio de racionalidad de una sociedad basada en los afectos a una sociedad basada en los logros individuales. Esta teoría identificó etapas evolutivas de desarrollo de los pueblos. El eslabón perdido entre los ámbitos micro y macro del desarrollo social, sostiene Lechner (2000:71), es «una desventaja a la hora de analizar conjuntamente las relaciones de confianza generalizada y de asociatividad y, por otra parte, las normas de reciprocidad y de compromiso cívico vigentes en la sociedad». Las relaciones de confianza entre los individuos y 
el compromiso cívico dependen de las oportunidades y las restricciones que ofrece el contexto histórico-social.

La modernización parte de la premisa de que el desarrollo es un proceso evolutivo inevitable que incrementa la diferenciación social que crea sus instituciones económicas, políticas y sociales que siguen el patrón de desarrollo occidental. El desarrollo es un proceso de cambios dinámicos inducidos mediante políticas y estrategias impulsadas por diferentes agentes económicos y actores políticos. Las investigaciones de las acciones estratégicas, preferencias y actitudes de los actores de la transición política se centran más en la elección racional que en una dimensión más subjetiva. Las teorías del derrame ya desacreditadas en la economía desarrollista se mantuvieron como la respuesta al dilema de la distribución y la teoría de la modernización fue resucitada para pronosticar la última convergencia de los sistemas económicos y políticos a través del globo.

Esta diferenciación social y una creciente disociación de la vida social son producto de los procesos de modernización, los cuales traen inestabilidad. Los procesos de modernización generan aprendizajes rápidos y traen consigo un incremento en las demandas de bienes y servicios e inflación de las expectativas para satisfacer las necesidades y deseos, lo cual no siempre desarrolla la infraestructura y capacidad para lograrlo. La modernización era vista como un proceso de diferenciación estructural e integración funcional donde tenían lugar las categorías de clasificación del mundo, pero para Giddens $(1984,1990)$, la teoría de la modernización es vista como un proceso de distanciamiento espacio temporal, en el cual el tiempo y el espacio se desarraigan de un espacio y un tiempo concretos, proceso que es más bien postmoderno.

\section{Estrategias de modernización neoliberal y estructuralista}

El neoliberalismo es una versión nueva del liberalismo económico, el cual además tiene aplicación en la economía internacional y no solamente dentro de las fronteras nacionales. La diferencia entre socialdemocracia y neoliberalismo es que éste quiere la menor intervención política posible (dejando a la regulación del mercado la tarea de poner orden) y la socialdemocracia tiende a regular la mayor cantidad posible de aspectos de la vida humana. En este tira y afloja estamos entre unos regímenes y otros y entre unos períodos históricos y otros.

La estrategia de modernización neoliberal se ha absolutizado bajo un dogma ortodoxo que no distingue diferencias de desarrollo entre los Estados nacionales. La modernización neoliberal diferencia las esferas económica, política y social, demanda el ejercicio de nuevas reglas de operación y regulación de los comportamientos sociales, los cuales se acompañan de una creciente inestabilidad en los procesos de cambio. La modernización neoliberal 
separa a la subjetividad, la considera un proceso autónomo e inconexo que genera tensiones cuando, de acuerdo con Lechner (2000), ambos fenómenos son complementarios y es necesario relacionarlos, ya sea en forma espontánea conforme a la apuesta del liberalismo decimonónico o establecida por el Estado conforme al modelo socialdemócrata.

La estrategia de modernización neoliberal se ha absolutizado bajo un dogma ortodoxo que no distingue diferencias de desarrollo entre los Estados nacionales. Los ámbitos de la modernización del Estado implican cambios en las tareas tradicionales, el funcionamiento de las instituciones políticas, la productividad del sector privado y la formulación e implementación de políticas públicas en las diferentes áreas.

La modernización era vista como un proceso de diferenciación estructural e integración funcional donde tenían lugar las categorías de clasificación del mundo. El enfoque estructuralista de la modernización acepta los costos sociales como exigencias de la implementación del modelo y apuestan a la gobernabilidad que acota la subjetividad.

El estructuralismo incorpora las relaciones e interacciones entre el centro y la periferia, las condiciones y características estructurales económicas, sociales y políticas del sistema capitalista que determinan el desarrollo y el subdesarrollo de los pueblos. Para servir a las elites capitalistas transnacionales, las elites capitalistas locales requieren de Estados recolonizados fuertes para salvaguardar los objetivos imperialistas y con capacidad para imponer y garantizar la ejecución de las reformas estructurales y de estabilización económica, a pesar de las movilizaciones populares oponentes.

$\mathrm{Ni}$ la teoría de las relaciones internacionales, ni tampoco la teoría de la democracia, alcanzan a establecer un marco de referencia que sustente la conceptualización como la práctica del desarrollo democrático de los pueblos y sus relaciones con el capitalismo moderno o neocapitalismo, bajo un contexto global, a pesar de su potencial latente de autoritarismo. No obstante, algunos principios del capitalismo no necesariamente promueven la democracia, tales como aquellos que son «concebidos como la expresión de demandas de la razón» (Amín, 2001:45), entre otros, la propiedad privada, la competencia de los mercados, los principios de emprendedores, etc. Las manifestaciones de este avance del capitalismo emergente se enmarcan en la paradoja consistente en que, mientras se centra en función de los mecanismos autorreguladores del mercado, por otro lado desencadena reacciones en contrario para contrarrestar y compensar los efectos de los mecanismos perversos del mercado.

$\mathrm{El}$ «movimiento de derecho y desarrollo» que se desarrolló en los setenta, analizó, desde un etnocentrismo, la vinculación de los sistemas de derecho al proceso de desarrollo económico para lograr metas de desarrollo socioeconómico a través de instrumentos jurídicos, especialmente de derecho público, de funcionamiento del mercado. El etnocentrismo institucional desconoce la endogeneidad del desarrollo institucional considerando los 
riesgos de las adaptaciones institucionales. Desgraciadamente faltó sistematización teórica para fundamentar el papel del derecho en el desarrollo económico, ya que solamente se fundamentaba en los trabajos de Weber sobre los análisis de modernización y en la jurisprudencia sociológica.

El término desarrollo puede conceptualizarse como los procesos de transición de los pueblos hacia economías industriales, capitalistas y modernas, así como la obtención de mejores niveles de calidad de vida humana y bienestar material, considerado como la satisfacción de un conjunto de necesidades, deseos y temores. La transición de una economía basada en materiales. Cualquier transición de modelo económico, para que sea exitosa, requiere de la intervención estatal para establecer las reglas del juego mediante procesos de institucionalización. La teoría de transiciones encuentra barreras institucionales para consolidar la democracia que no se corresponden necesariamente con una política moderna, ni tampoco con una mejor distribución de la riqueza. La sociología política y el institucionalismo de la ciencia política fundamentaron conceptualmente la noción del buen gobierno empujando la instauración de procesos de gobernabilidad democrática y el análisis de los procesos de informalización de la política. Los procesos de institucionalización efectuados durante los últimos años del siglo pasado desestructuraron y fueron disfuncionales en las relaciones entre la economía y la política, causando graves crisis.

La nueva relación social que se globaliza es la que articula la propiedad privada de los medios de la producción como la regla que da certeza al funcionamiento del mecanismo del mercado. La «macrodictadura total» del neoliberalismo, como sostiene el obispo de Sao Felix do Araguaia, Brasil, que se impone como pensamiento único con sus «teólogos del diablo» y su postmodernidad narcisista (Fazio, 2000: 4). El mercado es una construcción social que operacionaliza relaciones sociales. No obstante, el poder social del programa neoliberal emerge de los intereses que mantienen quienes ostentan el poder económico que da forma al poder político.

Hacia dentro del Estado-nación se presenta la lucha de clase para lograr el aseguramiento del acceso a los recursos mediante la conquista del poder. La implementación de las políticas de ajuste estructural en los países del tercer mundo ha producido consecuencias inesperadas, algunas contrarias a las metas de desarrollo original. La difusión de los valores y el proyecto económico dejaron poco espacio a la reconceptualización del desarrollo en términos de éxito en el mercado. El desarrollo fue una cuestión de instalar la correcta orientación de valores y normas en las culturas del mundo no occidental, así como de permitir a su gente entrar en la riqueza moderna creando las instituciones económicas y políticas del mundo occidental avanzado.

La implantación se realiza a través de las denominadas reformas administrativas orientadas a la modernización de las estructuras del aparato burocrático, la más reciente de las cuales se ha denominado la revolución gerencial que intenta redefinir el sistema burocrático sin alcanzar los benefi- 
cios esperados. La modernización de la gestión pública propuesta bajo nuevos supuestos explicitados en el paradigma de la Nueva Administración Pública, la cual se instrumenta en la reforma administrativa, ha tenido resultados en lo que se refiere a la prestación de servicios públicos que no han sido del todo positivos (Ramírez Alujas, 2002). Las reformas pretenden el funcionamiento eficiente del mercado mediante la reducción de los costos de transacción, procesos de descentralización y modernización de la administración pública. El cambio institucional de los servicios públicos con una orientación hacia la acción social, centrado en los valores de la cultura cívica y en los valores del capital social, es muy complejo, debido a la racionalidad instrumental del enfoque de la eficiencia económica.

Las funciones públicas contingentes toman en consideración aquellas actividades que pueden ser subcontratadas (outsourcing) o privatizadas y que desestructuran las principales funciones del Estado moderno a las que Dror (1995: 222) denominó como «las funciones de orden superior» del Estado. El cuestionado sistema de méritos en la función pública constituye una forma moderna de la institucionalización orientada por una economía de libre mercado, se fundamenta en los bienes económicos, bienes jurídicos y funciones sociales. Por otra parte estamos viendo desaparecer la regulación colectiva de muchas funciones que hasta no hace mucho considerábamos comunes: las compañías telefónicas, el correo, los ferrocarrilles, etc. Faguet (1999) sugiere que la descentralización es un nexo entre las decisiones de inversión pública con las necesidades locales, de tal forma que los procesos de descentralización fiscal se identifican como procesos de descentralización administrativa que permite a los gobiernos locales definir sus propias políticas de ingreso y gasto mediante la innovación. Los gobiernos locales tienen que jugar un papel protagonista como agente del desarrollo económico.

La lógica de la descentralización es la territorialización de la política pública en espacios delimitados en localidades y regiones, en las cuales se formulan e implementan las políticas públicas o policies. La estrategia de crecimiento se orienta hacia el desarrollo local basado en los proyectos municipales impulsados por los actores locales. El gobierno local requiere de una sociedad civil asentada en un territorio con un conjunto de valores y normas que sustenten la identidad con un sistema político que le proporcione el poder suficiente para la transformación de procesos de generación de bienestar y riqueza.

Las corrientes neoliberales y neoestructuralistas alcanzaron un cierto nivel de consenso en sus propuestas sobre las funciones del mercado y del Estado en la década de los noventa del siglo pasado, sobre la base de un reconocimiento de que son elementos complementarios más que antagónicos, capaces de desarrollar una relación armónica facilitadora de procesos de desarrollo. Estado y mercado existen para representar los intereses de lo público y lo privado de una misma realidad social. De acuerdo al análisis de Dowbor (2001), segmentos sustanciales de la sociedad han empezado a pensar en 
términos de un «pequeño y eficiente Estado», para justificar los procesos caóticos de privatización, posponiendo el problema esencial de a quién y cómo debe servir el Estado. El principal punto en la acción no es cortar partes del gobierno, sino hacerlas trabajar mejor y con otros fines.

Los procesos de modernización del Estado no necesariamente significa debilitamiento, ya que deben comprender sus funciones tradicionales de seguridad, impartición de justicia, defensa, relaciones exteriores, etc., responsabilidades del funcionamiento de las instituciones políticas, creación de un ambiente propiciador de una actividad productiva del sector privado para el crecimiento y el desarrollo, formulación e implementación de una política social y políticas públicas apoyadas por decisiones políticas. Esto debe proveer el marco de referencia en el que las estrategias prospectivas, las instituciones representativas y los proyectos que hacen a la política social el sustento del desarrollo. De acuerdo a Morales-Gómez y Torres (2000), la agenda de una política social para el desarrollo debe asignar prioridad a los siguientes aspectos:

El Estado debe tener las atribuciones necesarias para establecer las reglas de funcionamiento de los mercados mediante procesos de democracia participativa. En una sociedad más desarrollada se fortalecen el Estado, el mercado y la sociedad civil, como instrumentos del desarrollo mismo. En el contexto institucional se establecen las relaciones entre los actores y la dinámica histórica de los tipos sociales en la dialéctica de la racionalidad e irracionalidad de sus comportamientos relacionados con las estructuras, interacciones y funciones de las instituciones en el contexto social.

\section{Postmodernidad}

La noción Kantiana de arqueología designa la historia de lo que vuelve necesaria una cierta forma de pensamiento. La etapa de la cientificidad que adoptó las formas de la ciencia natural y exacta corresponde al estructuralismo. La arqueología mantuvo la creencia en las ciencias sociales alternativas que estudian sistemas, estructuras y formas. A partir de los años setenta se opera el periodo genealógico con la influencia del perspectivismo y Nietzsche en una actitud militante en contra de la represión, una desconfianza hacia el discurso académico que se expresa en el postestructuralismo, identificado con el postmodernismo irracionalista y nihilista que rechaza el método científico, el pensamiento racional y el abuso de la ciencia como metáfora. La transición entre la arqueología y la genealogía está marcado por las reflexiones discursivas como expresión del poder.

La tendencia postmoderna de pensamiento apareció recientemente como expresión o aprehensión de una realidad social específica que hace referencia al pensamiento emergente de la modernidad tardía o de la era postindustrial, manifiesto en las condiciones de vida específicas de los grandes centros 
urbanos de los países desarrollados, o bien como una cultura conformada por un conjunto de modos de vida en las regiones hiperindustrializadas. Giddens (1993) opone a la idea de postmodernidad la de modernidad radicalizada y hace la critica del movimiento postestructuralista de donde se deriva y que debe superarse porque considera que hay insuficiencias en los análisis de la modernidad de los siglos XIX y XX.

Se reprocha que el postmodernismo puso el último clavo en el ataúd de la Ilustración y la izquierda enterró los ideales de justicia y progreso. La esencia de la Ilustración es el ejercicio racional de la critica y se perfecciona enfrentando sus propios defectos de raciocinio.

Una nueva época quedó delimitada a partir de 1989 con la implosión del sistema socialista soviético y el auge de una nueva concepción más centrada en la mera subjetividad de la vida y del mundo denominada postmodernidad. El capital social tiene carácter instrumental y expresivo, fortalece la subjetividad frente a la modernización y es también una relación puramente expresiva y gratuita como fin en sí misma y que además crece en la medida en que la modernización avanza (Lechner, 2000). Newton (1997) examina la subjetividad del capital social compuesto de valores y actitudes que afectan las formas de relación entre las personas. Pero también, la subjetividad es refugio o resistencia contra el modelo de pensamiento único hegemónico (Bourdieu, 1998).

La globalización es consecuencia ineludible de la modernidad capitalista que deriva en la postmodernidad, y por lo tanto, en un preconizado relativismo que socava la crítica social, para el cual la objetividad es una mera convención social. Un inmovilismo discursivo está invadiendo a la sociedad postmoderna. La globalización exalta al individualismo de las personas, las convierte en meros instrumentos homogéneos de producción y consumo y las reduce a simples mercancías que se compran y venden sin que las diferenciaciones culturales sean obstáculo. A mayor globalización, más avance tiene el individualismo, lo que afirma la tendencia hacia el autoritarismo del sistema capitalista. Se vive en un mundo en el que la adquisición y el consumo son considerados como las marcas de éxito personal y no lograrlo es una marca de fracaso.

Si la modernidad capitalista fue la creadora del Estado-nación y sus principales creaciones, como una sociedad y mercado nacionales, fronteras, ejércitos, etc., cuando el capitalismo entra en crisis, aunque muy discutible, entonces necesariamente entran en crisis todas estas instituciones, ya en transición hacia la postmodernidad. La globalización puede ser vista como una continuidad del voluntarismo para establecer el ideal de una sociedad justa y afluente mediante la creación del Estado de Bienestar y de las tesis desarrollistas, pero con adaptaciones a la cultura de la postmodernidad. La postmodernidad cuestiona la legitimidad del desarrollo alcanzado por la modernidad y la universalidad de sus valores y procesos, el reduccionismo economicista, su enfoque etnocéntrico y la unidimensionalidad de su interpretación. 
La postmodernidad cuestiona las variables sociales, culturales, del medio ambiente, políticas y éticas de la ecuación del desarrollo y su proyecto modernizador. La inclinación del posdesarrollo sobre «el lugar», la ecología política y la geografía postmoderna al estudiar la globalización, permite reconocer los modos de conocimiento y modelos de naturaleza basados en lo local (Escobar, 2000:172). El desarrollo en la globalización ha sido en general capitalocéntrica porque sitúa al capitalismo «en el centro de las narrativas de desarrollo, tendiendo, en consecuencia, a devaluar o marginar cualquier posibilidad de desarrollo no capitalista... la naturalidad de la identidad capitalista como plantilla de toda identidad económica puede ser puesta en cuestión» (Graham y Gibson, 1996: 146) por diversas opciones de desarrollo económico propias del mismo posdesarrollo que valoran los modelos locales no necesariamente complementarios, ni opuestos ni subordinados al capitalismo. Estos modelos locales desafían «lo inevitable» de la penetración capitalista con los procesos de globalización y, por lo tanto, se puede decir que todo lo que surge de la globalización encaja en el guión capitalista. Muchos de los habitantes de la regiones menos desarrolladas viven bajo condiciones que pueden ser descritas como modernidad desigual más que postmodernidad.

Las orientaciones postmodernas que son condicionantes de los principales agentes de los procesos de globalización, las corporaciones transnacionales y multinacionales, al decir de Santos (1993) son la unicidad de la tecnología, del tiempo y de la plusvalía como motor del desarrollo. El tiempo tiene poco significado y el espacio se comprime como resultado del avance tecnológico.

La ciencia postmoderna proporciona las bases metodológicas y de contenido para un proyecto económico-político. Este proyecto concibe «la trasgresión de las fronteras, el derrumbamiento de las barreras, la democratización radical de todos los aspectos de la vida social, económica y política» (Sokal y Bricmont, 1999: 83). La democratización se refiere a las reformas políticas que introducen mecanismos esenciales para una mayor competencia electoral, modernización de partidos políticos y creación de nuevas instancias de representación ciudadana y una participación más abierta de la sociedad civil, así como una distribución más equitativa de la riqueza y un mejor equilibrio del ejercicio del poder en la comunidad.

En el postmodernismo no existen fronteras ni alternativas para el futuro, sino una reiteración de lo mismo a través del empleo de las tecnologías. En el periodo avanzado del postmodernismo se forman elaboraciones que desarrollan las tesis de las «técnicas de sí». En estas etapas sucesivas, por ejemplo, Foucault intenta transplantar las ciencias naturales y exactas a otros campos al mismo tiempo que es escéptico del método racional y critica el humanismo.

Las tendencias derechistas del postmodernismo se expresan con planteamientos tecnocientíficos conservadores de filósofos del stablishment que 
limitan las alternativas de acción política para superar la etapa de desarrollo de la humanidad, como en el fin de la historia de Fukuyama. El postmodernismo radical que rechaza toda manifestación de la racionalidad es considerado como un relativismo cognitivo y es cuestionado por considerarlo un cientifismo dogmático frente al prestigio de la ciencia basada en el modelo racionalista.

Si la característica fundamental de la modernidad es la densidad de los cambios, la característica principal de la postmodernidad es la aceleración de estos cambios caracterizados por su complejidad e incertidumbre, por una fenomenología caótica (teoría del caos) que modifica constantemente los procesos económicos, políticos, sociales, culturales, etc. En la postmodernidad prevalece la idea de que la realidad es compleja y multicausal, en cambio continuo, que acepta diferentes racionalidades con relación a las variables a optimizar y que nada está garantizado o predeterminado.

Una mayor velocidad es la característica de todos los aspectos de las funciones de las organizaciones, desde las comunicaciones internas al desarrollo de productos para el intercambio competitivo. La velocidad tiene efectos en el decrecimiento de las imperfecciones del mercado, el incremento de la volatilidad a que deben responder las organizaciones y el decremento de los tiempos de estímulo respuesta involucrados en actividades organizacionales prosaicas. Existe un hueco entre el desarrollo rápido de nuevas formas organizacionales en práctica y la capacidad de las perspectivas existentes en la teoría.

Los conceptos de organización postburocrática, postmoderna, la organización postemprendedora y la firma flexible se refieren a nuevos principios organizacionales y expresan los nuevos paradigmas en las formas organizacionales. Otros aspectos específicos de estos paradigmas incluyen el federalismo, la corporación virtual, la corporación reingenierada, la compañía creadora de conocimiento, la organización «ambidexterus», de alto desempeño o sistemas de trabajo de alto compromiso, la organización híbrida y la «solución transnacional», etc. La solución transnacional es una visión de una red integrada en la cual el centro corporativo guía los procesos de coordinación y cooperación entre las unidades subsidiarias en un clima de toma de decisiones compartidas, mezcla la jerarquía con la red y retiene la creación del valor en una corporación (Bartlett and Ghoshal, 1998: 113). Cambios en las metas de las organizaciones para responder a la incertidumbre, el enfoque estratégico en el diseño de procesos y estructuras, un énfasis en lo social e interpersonal y una reemergencia de la legitimidad.

La lógica cultural del capitalismo tardío es el postmodernismo donde el espacio se interpreta como un símbolo y una realidad privilegiada. El concepto de espacio evolucionó de una concepción territorial física a una concepción más dinámica y multilineal. Arellanes Jiménez caracteriza este nuevo concepto de espacio como un concepto dinámico, abierto, cambiante, flexible y multilineal e histórico que se va aplicando a diversas circunstancias, coyunturas, cambios, actores, sujetos y relaciones. 
La desterritorialización del Estado-nación está dando lugar a nuevas formas espaciales geopolíticas y geoeconómicas. El surgimiento del Estado postnacional evoluciona el concepto de nación como el invento moderno que legitima el dominio de un pueblo politizado sobre un territorio determinado. Esta tendencia hacia el sí mismo multilocal es ya una característica de esta modernidad capitalista avanzada, del mismo modo que la tendencia hacia el espacio poliétnico o desnacional (Sloterdijk, 1999).

La ciudad global es multinodal y policéntrica, guiada y coordinada por un punto de una red flexible que se interrelaciona en forma complementaria con otros niveles regionales, dando lugar a una sociedad red de la era de la información. Al mismo tiempo que la cultura se vuelve más homogénea en las ciudades globales, también ocurren procesos de diferenciación cultural, dando lugar a procesos de desterritorialización de culturas con el florecimiento de culturas locales. Las ciudades globales son lugares de creación de nuevas identidades culturales y políticas para sus habitantes, que comparten una cultura masiva global sofisticada, como parte de un proceso de McDonalización del mundo paralelo a la polarización socioeconómica.

Pero la exclusión y segregación humana tiene serias consecuencias, que se expresan en comportamientos antisociales, tal como Bauman (1998: 57) precisa: una parte integral del proceso de globalización es la progresiva segregación espacial, la separación y la exclusión.

Las tendencias neotribales y fundamentalistas, reflejan y articulan la experiencia de la gente al recibir los coletazos de la globalización como la extensamente celebrada «hibridización de la top culture: la cultura en la cima globalizada». La cultura está siendo globalizada igualmente que el comercio, cuya tendencia es a la destrucción de las culturas locales, a la homogeneización y estandarización que destruye la diversidad y vitalidad cultural y social.

Los impactos transculturales de los procesos de globalización se manifiestan en la estandarización universal de comportamientos y valores que se reproducen y adaptan localmente con los identificados con los patrones de la cultura occidental: cosmopolita, capitalista, urbana, moderna, empleo del idioma inglés como lenguaje universal, etc. La globalización universaliza los valores de la cultura anglosajona. Aunque en términos generales se puede sostener que el aparato institucional cultural está en crisis. La imposición de los valores y la cosmovisión de la cultura occidental a los pueblos colonizados ha dado como resultado grandes disfuncionalidades.

El mayor daño que el postmodernismo causa a los países en desarrollo es una guerra de culturas para convertirse en consumidores acríticos de culturas foráneas si se considera como el reflejo múltiple de la cultura de la postmodernidad donde el trabajo de la Ilustración no ha concluido y donde se identifican el irracionalismo postmoderno con las mentalidades irracionales que no acaba de realizar la civilización. La postmodernidad alienta a revisar las culturas y a replantear sus relaciones con la visión de los valores occiden- 
tales. Hay escasas evidencias de que la región latinoamericana consista de sociedades postmodernas o que se esté moviendo a una era postmoderna.

Lechner (2000) señala que en la postmodernidad inciden como tendencias el desmoronamiento de la fe en el progreso y una creciente sensibilidad acerca de los riesgos fabricados por la modernización; el auge del mercado y el consiguiente debilitamiento de la política como instancia reguladora y el cuestionamiento de la noción misma de sociedad como sujeto colectivo capaz de moldear su ordenamiento. La postmodernidad de la cultura política se caracteriza por una fragmentación de valores compartidos por las colectividades y el distanciamiento de los ciudadanos a las instituciones, marcado por una creciente desconfianza que provoca crisis de las democracias institucionalizadas.

En este tipo de democracia, el ciudadano se adapta con una participación limitada por los entramados de las redes del poder para formular y exigir el cumplimiento de las demandas. Los mecanismos de coordinación y comunicación horizontal con la ciudadanía permiten la creación de un sistema complejo de redes que facilita la participación democrática para la toma de decisiones y para la implementación de las políticas públicas. La toma de decisiones debe realizarse al más cercano nivel de la población involucrada. Según Prats (2001), la democracia debe satisfacer como estándares la participación efectiva, la igualdad del voto, un entendimiento informado y el control sobre la agenda

De acuerdo con estos autores, las fuentes de un postmodernismo que se mueve hacia la izquierda política son el descontento con la izquierda ortodoxa, su desorientación y la ciencia como un blanco fácil. La izquierda ha asimilado y repetido hasta la saciedad la retórica de la doctrina del libre mercado y ha denunciado el desmantelamiento de las funciones del libre mercado.

Sin embargo, entre sus efectos negativos se mencionan la pérdida de tiempo en las ciencias humanas, una confusión cultural oscurantista y el debilitamiento de la izquierda política.

Las críticas al desarrollo de la postmodernidad se interesan por los paradigmas alternativos que enfatizan el establecimiento de metas desde una tradición y cultura, participación en la toma de decisiones y en la acción de contenidos de desarrollo (Goulet, 1999). El modelo clásico racional de toma de decisiones que marca etapas sucesivas claramente distinguibles en la época moderna es diferente que el modelo de interacción estratégica de la postmodernidad. Las etapas del proceso de decisión racional de la modernidad son la preparación, determinación, ejecución, evaluación y ajuste de la política, los cuales requieren de procedimientos burocráticos administrativos racionales y una administración fuerte de sujetos obedientes quienes bajo las reglas del juego establecidas se orientan por el bien común. En ocasiones, desde la perspectiva de postmodernidad, los actores que se desvían de las reglas del juego son apreciados positivamente por las posibles contribuciones que realizan. 


\section{Modernidad y procesos de globalización}

La globalización constituye una etapa superior del desarrollo mundial del capitalismo que surge a partir de cambios radicales y profundos en la economía política y la política económica fundamentadas en el neoliberalismo que pretende transnacionalizar su impacto. Las dimensiones del cambio económico, político y social mundial son determinadas por la reestructuración del capitalismo globalizador.

También pueden entenderse los actuales procesos de globalización como resultado de una tendencia continuada, por lo menos en los últimos cinco siglos, del desarrollo del capitalismo, hasta llegar a la fase actual denominada neocapitalismo o capitalismo tardío, mediante el análisis más detallado de sus rasgos característicos que muestran diferentes manifestaciones y formas de expresión. La división internacional del trabajo, la economía mundial capitalista, el sistema de Estados-nación y el orden militar mundial son las dimensiones de esta globalización. En los procesos de globalización, el capital se globaliza mientras que el trabajo se localiza.

Giddens (1990: 201) señala que la modernidad extendida da origen a la globalización entendida como «la intensificación a escala mundial de las relaciones sociales que enlazan localidades muy distantes, de tal modo que lo que ocurre en una está determinado por acontecimientos sucedidos a muchas millas de distancia y viceversa». En la relación entre lugar y cultura, los lugares son creaciones históricas que se deben explicar, no asumir, y en esas explicaciones se describen las formas en que la circulación global de capital, conocimiento y medios de comunicación configuran la experiencia de la localidad.

La economía encuentra límites para explicar, describir y predecir los cambios que los procesos de globalización están motivando. Para analizar los diferentes niveles tales como por ejemplo, el individuo, la sociedad, el Estado, el mercado, la región, lo internacional, etc., debe considerarse toda la complejidad estructural y holística del sistema global. Las instituciones locales, nacionales, regionales y mundiales ponen en marcha complejos sistemas regulatorios de políticas y procesos de toma de decisiones.

Por otro lado, la teorización holística de la economía política internacional es una forma contestataria de la creciente globalización neoliberal y a la correlativa representación democrática. La multi-dimensionalidad de la globalización está estrechamente vinculada con la idea de conectividad compleja como una condición del mundo moderno (Tomlinson, 1999). Por conectividad compleja el autor entiende que la globalización se refiere a la red de interconexiones e interdependencias que rápida y densamente se desarrollan y que caracterizan la vida social moderna. McGrew (1990) sostiene que la globalización constituye una multiplicidad de ligamientos y conexiones que trascienden a los Estados-nación, y por implicación a las sociedades, lo cual forma el sistema mundo moderno. Define el proceso a través del cual los 
eventos, decisiones y actividades en una parte del mundo puede tener una consecuencia significativa para los individuos y las comunidades en partes bastante distantes del mundo. Una de las características de la globalización es que más que desarrollarse un nuevo proceso, se han intensificado e interconectado viejos procesos. Lo que hay es una profundización de los procesos, más que un cambio cualitativo en la estructura global de la economía.

Así, la globalización es el triunfo de la teoría de la modernización que homogeneiza y estandariza valores en los principios del capitalismo y la democracia, estimula el crecimiento económico y promueve los valores de la democracia, aunque incrementa las condiciones de inestabilidad e incertidumbre. Sin embargo, lo que queda claro es que el crecimiento económico no es causa de la democracia. La acción gubernamental tiene bajo su protección la producción de este crecimiento económico y es una de sus principales preocupaciones. Esta aseveración es bastante discutible, si en realidad es la globalización un proceso inevitable y que además escapa al control de los agentes económicos y actores sociales y políticos. Las redes de actores individuales y colectivos «representan un nexo sobresaliente en la relación entre las personas y los sistemas funcionales» (Lechner, 2000: 28).

No obstante, el Estado considerado como un importante actor social sigue jugando un papel importante en la promoción del crecimiento económico y el desarrollo equitativo y equilibrado entre las diferentes regiones y localidades. Aziz Chaudry (1993) sugiere que las viejas cuestiones para reconciliar los objetivos de crecimiento y equidad fueron reemplazadas por las certezas de los economistas monetaristas.

\section{El final de la modernidad organizada}

La modernidad erige al Estado-nación como una forma de gobernabilidad para garantizar un espacio a la nación que necesita ejercitar su vocación histórica. «En cualquier sistema económico, los poderes públicos deben responsabilizarse de la existencia de un orden económico, en el que el ejercicio de los derechos y libertades económicas de los individuos y de los grupos sociales no perjudiquen a las terceras personas, ni atenten contra el interés general» (Asenjo, 1984: 44). Los sistemas económicos están en constante transformación, al igual que los sistemas políticos basados en los Estadonación se están disolviendo aceleradamente, y en muchos de los casos, están generando al interior de la sociedad, conflictos, caos y contradicciones con serias rupturas intranacionales e internacionales.

El capitalismo globalizador o neocapitalismo genera tensiones que se reflejan en las crisis económicas, políticas, sociales, culturales, educativas, en el medio ambiente, etc. Los agentes económicos y los actores políticos se encuentran en una carrera absurda de competencia por alcanzar una modernidad que termina en una crisis económica, social, ecológica y moral. Al res- 
pecto, Wallerstein (1997) sentencia: «Mi propia lectura de los pasados 500 años me lleva a dudar que nuestro propio sistema mundo moderno sea una instancia de progreso moral sustancial, y a creer que es más probablemente una instancia de regresión moral». Este sistema mundo no ha sobrevivido de la crisis moral que marca el final del milenio. El sistema mundo capitalista funciona y evoluciona en función de los factores económicos. Esta tendencia y otras son las causantes de lo que Wagner (1997: 12) denomina el final de la modernidad organizada.

La modernidad implica el desarrollo democrático y, por lo tanto, es «la adopción del principio de que los seres humanos individual y colectivamente (esto es, como sociedades) son responsables de su historia» (Amín, 2001: 36). El final de la historia y la continuidad del sistema económico han sido declarados por los agoreros del desarrollo capitalista, el que a pesar de las crisis sobrevive como la última utopía erigida en el modelo único y por tanto hegemónico.

La transnacionalización del Estado presupone la del capital y de la sociedad civil no sin provocar conflictos en el asentamiento del Estado nación o en la dualidad nacional-global. Existen muchas lógicas en la moderna sociedad que compiten y son inconsistentes, pero la presencia y extensión de los conflictos permanecen para ser evaluados empíricamente. Son las empresas transnacionales y multinacionales las que configuran el actual poder que tienen los Estados imperialistas, que derivan a sus comparsas, las instituciones financieras internacionales, a efecto de controlar los flujos de la economía internacional y mundial, dotadas con suficiente poder para evaluar y sancionar el comportamiento económico de los Estados nacionales mediante premios a ganadores y castigos a perdedores, que finalmente afectan a los niveles de vida de los ciudadanos.

La globalización económica que impone áreas de integración regional e instituciones supranacionales tiene un impacto evidente en la formación de nuevas naciones y en las funciones del Estado a partir del avance de los procesos de descolonización y separación, de una evidente erosión de los sistemas de seguridad nacionales que inciden en sentimientos de identidad nacional, regional o local. La propuesta de la dependencia institucional sostiene que éstas son preferidas por ser aquellas que están más cercanas a la mayoría original o al diseño de negociación más posible. Los gobiernos locales tienen un papel importante como agentes del desarrollo económico.

Los procesos de globalización, aunados al crecimiento incontrolable de megalópolis en algunos países menos desarrollados, crean nuevas formas de organización y desorganización que someten a la población a una brutal competencia de tal forma, que establecen similitudes y diferencias donde se mezclan rasgos de la modernidad y la postmodernidad marcadas con la realidad de las sociedades desarrolladas. El vínculo social es un recurso del capital social para el desarrollo económico, el cual se presenta en forma neutral para ser aprovechado mediante diferentes estrategias. De acuerdo a 
Bourdieu (1992), capital social es la totalidad de los recursos actuales y potenciales asociados con la posesión de una red perdurable de relaciones más o menos institucionalizadas de conocimiento y reconocimiento común. Así, en esta perspectiva, el capital social pertenece al individuo y de alguna manera explica cómo personas con igual capital cultural y económico obtienen diferentes logros. El capital social es un recurso acumulable que crece si se hace uso de él o se devalúa si no es renovado. Esta modernidad exacerba los derechos individuales sobre los derechos sociales.

Las manifestaciones multiculturales en estas sociedades hasta cierto punto configuran estos rasgos que por un lado desintegran la identidad individual y las referencias comunitarias, destruyen las estructuras familiares y sociales, así como las manifestaciones religiosas, culturales e intelectuales. Estas reacciones consideradas como irracionales frente a los excesos racionalistas de la organización se encuentran estrechamente vinculada con el ambiente económico, social y político.

De hecho, los defensores de la modernidad occidental pregonan el progreso científico y tecnológico de la humanidad mediante el establecimiento de los principios de libertad, igualdad y justicia para todos. La libertad e igualdad de acceso a las oportunidades de desarrollo inducidas por la globalización se reducen y supeditan a los intereses de los vínculos comerciales y los movimientos de capitales que dan por resultado la mundialización de la pobreza que se sostiene en una desigualdad acumulativa y no autocorrectiva que dificulta mantener un equilibrio.

No hay que perder de vista que mientras el capitalismo se recupera, la inmensa mayoría de los trabajadores ven disminuidos sus ingresos salariales y prestaciones sociales además de incrementos inusitados de desempleo. La modernización institucional y política y el crecimiento económico centrado en el desarrollo tecnológico no necesariamente crean empleos. El futuro de los trabajadores es muy incierto. Los países que cuentan con más mano de obra, deben especializarse en la producción y exportación de productos y servicios que empleen mano de obra. La movilidad de la mano de obra no se ha liberalizado, a pesar de los posibles beneficios disciplinarios que traerían al dominio del libre mercado. Esta estrategia de la globalización está dando por resultado una profundización de los niveles de pobreza mundial.

La globalización se perpetúa en los contenidos de la información y la comunicación excluyendo a más individuos, que quedan fuera de los beneficios de la nueva cultura e identidad global. Las ventajas comparativas de las naciones se expresan como las habilidades para adquirir, organizar, almacenar y diseminar la información mediante procesos de tecnología de información y comunicación. La creciente diferenciación entre los que tienen y no tienen es el reflejo en parte de quienes tienen y no tienen acceso a las tecnologías de la información y la comunicación. Por lo tanto, el intercambio de la información es un componente para el desarrollo sustentable que mejora la calidad de vida y les da mayor control a las personas. 


\section{Modernidad y postmodernidad como formas de sustentabilidad social}

Los modernistas asumen que la función primaria de la organización económica es la producción. Los postmodernistas asumen que la producción de cosas físicas es sobrepasada por la producción de bienes de información y servicios. Muchos de los habitantes de la regiones menos desarrolladas viven bajo condiciones que pueden ser descritas como modernidad desigual más que postmodernidad.

La orientación empresarial del Estado que busca la rentabilidad y la calidad total en todos los servicios que ofrece a un mercado de consumidores más que a ciudadanos, asume el bienestar como una función del poder adquisitivo de quien cuenta con los recursos para comprarla. En vez de sostener el crecimiento económico y una mayor igualdad social, la modernización de las sociedades del tercer mundo produjo varias consecuencias negativas no esperadas tales como el prematuro incremento de los estándares de consumo con muy poca relación a los niveles locales de productividad; la bifurcación estandarizada entre las elites capaces de participar en el consumo moderno y masas concientes de ello pero excluidas, presiones migratorias en tanto que los individuos y sus familias buscan ganar acceso a la modernidad moviéndose directamente a los países de donde proviene la modernidad (Portes, 1997).

Los procesos de globalización neoliberal incrementa las desigualdades sociales que debilitan el sistema democrático, agudiza sus contradicciones y lo hace incompatible con el capitalismo. La mano visible del capital transnacional asume funciones liberadoras de recursos en condiciones altamente especulativas en un mercado globalizado competitivo respondiendo a los intereses financieros de quienes lo controlan sin que necesariamente asuman supuestos para ampliar las capacidades económicas, sociales, políticas y culturales de los pueblos con menor desarrollo humano.

Los procesos de globalización sin el desarrollo informacional son excluyentes, selectivos y sólo benefician a una minoría. Los adelantos tecnológicos permiten un mayor acceso a los procesos de modernización política que implican la participación de la sociedad civil para la construcción propia de la estructura e infraestructura del propio desarrollo, más centrado en redes de cooperación y con procesos interactivos en un mismo nivel horizontal. No obstante, la revolución tecnológica parece propiciar un mayor desorden económico, político y social.

Desde la perspectiva de la modernidad, la corrupción es un fenómeno que se manifiesta en sociedades con regímenes políticos no evolucionados. La corrupción se define como el mal uso que se hace de la oficina pública para la ganancia personal. El principal objetivo de la corrupción es incrementar la ganancia privada. La corrupción está estrechamente relacionada con la pérdida de confianza de formas de cooperación y distribución de cos- 
tos y beneficios que se sustituyen por formas de competencia y de imposición de influencias. Desde la perspectiva de la moralidad, se establece la relación entre coacción y corrupción por ser moralmente reprochables. La corrupción de una sociedad está referida al sistema normativo que delimita los deberes institucionales y establece los papeles que desempeñan los decisores. La legitimación de un sistema normativo se realiza por otro superior, cuyo máximo nivel es la moral crítica o ética. Los deberes institucionales o posicionales se adquieren a través de actos voluntarios por quienes asumen los papeles (Garzón Valdés, 1995). La democracia representativa institucionalizada en el estado social del Derecho cumple con los requerimientos de la ética que convierte en inexcusable la lealtad de los decisores.

La modernización puede lograr la sustentabilidad social si se acerca a los fundamentos culturales de la sociedad. Los procesos de modernización implican el cálculo y control de los procesos sociales y naturales que corresponden al desarrollo de la racionalidad instrumental, que se contrapone al concepto de racionalidad normativa que se corresponde con la modernidad orientada a la autonomía moral y a la autodeterminación política. Esta perspectiva sociológica predijo correctamente la difusión de las orientaciones occidentales modernas y las formas institucionales para las tierras menos desarrolladas. La escuela sociológica completa vino a enfocarse más tarde en esta difusión global de las formas institucionales del centro avanzado a la periferia del sistema internacional.

Sin embargo, actualmente las funciones del Estado en la economía internacional son esenciales. Un liberalismo absoluto en el que el Estado solamente se ocupe del ejército y la policía no es hoy ya sostenible. A pesar de las tendencias neoliberales que limitan las funciones y actividades del Estado, su participación sigue siendo fuerte para regular los procesos económicos. En las sociedades fuertes administra la mitad del producto social, racionalizando sus actividades como la manera más efectiva para elevar la productividad social.

\section{Nuevos movimientos sociales y acción colectiva}

Los movimientos sociales internacionales recientes capaces de combatir los poderes económico-financieros son los primeros signos del descubrimiento colectivo de la necesidad vital del internacionalismo o, mejor aún, de la internacionalización de los modos de pensamiento y de las formas de acción. La evolución de la organización política de la sociedad en comunidades organizadas para lograr sus fines mediante la práctica de un democracia participativa que apoya al Estado para administrar el interés público es contraria a los fines de la modernidad capitalista.

La globalización está afectando el efecto de calor de hogar político-cultural protegido por el Estado nacional moderno, por lo que toda comunidad 
política real tendrá que dar una respuesta al doble imperativo de la determinación por el espacio y la determinación por el sí mismo como punto de convergencia para una identidad regional. La identidad se expresa en una comunidad de intereses a través de medios espaciales territoriales nacionales e internacionales. La política exige por lo menos un uso comunitario sometido a reglas que se regulan por leyes, desde el impuesto obligatorio a las reglas de tráfico, pasando por la reglamentación de la construcción, el comercio, etc.; de acuerdo a Putnam (1993: 183), «la comunidad cívica tiene profundas raíces históricas. Ello es una observación deprimente para quienes ven la reforma institucional como una estrategia de cambio político».

De hecho, los procesos de globalización y modernización no eliminan la capacidad de acción colectiva para oponerse al poder, reivindicar derechos humanos, políticos, cívicos, sociales, etc., por lo que las condiciones de inestabilidad e incertidumbre se incrementan. En los países en vías de desarrollo, la acción colectiva plantea toda una problemática para lograr avances institucionales y organizacionales. Las estrategias de competitividad sistémica que requieren los procesos de la globalización entre las personas involucradas están determinadas por los beneficios que reciben de la acción colectiva los participantes, quienes en ocasiones en un comportamiento del clásico «gorrón» causan más problemas cuando se aprovechan para sacar ventajas de su poca o nula contribución al esfuerzo sin los pagos correspondientes de la cooperación. Sin embargo, en problemas de acción colectiva con elementos distribucionales es difícil ponerse de acuerdo en los objetivos y no queda claro qué resultado colectivo es el deseable. Los soluciones políticas implican mecanismos para encontrar acuerdos y para exigir su cumplimiento.

El dilema de la acción colectiva característicamente emerge en un nivel transaccional cuando los agentes son independientes, son conscientes de su interdependencia y no existen agencias que puedan coordinar las acciones de los agentes involucrados. Al aumentar el tamaño de la agencia en las estructuras burocráticas, con controles jerárquicos, la autoridad se distorsiona. Las formas burocráticas familiares incluyen el control jerárquico y las relaciones de autoridad, fronteras relativamente fijas y autoridad de arriba hacia abajo.

La participación ciudadana en el juego político es la base de todo sistema democrático. Los mecanismos de participación ciudadana dan fundamento al ejercicio democrático de las estructuras institucionales de gobernabilidad que facilitan las interacciones entre la sociedad y los ciudadanos. Los mecanismos de participación política en las comunidades políticas democráticas adquieren nuevas dimensiones cuando se busca la representatividad de los ciudadanos. Sin embargo, la utilización de estos mecanismos puede prestarse a la manipulación de la sociedad. En general, los ciudadanos participan poco o son indiferentes en los asuntos políticos, no se identifican con el juego de la política ni con políticos o partidos políticos a los que desdeñan y en ocasiones desprecian. Según la estructuración flexible del Estado-red en el concepto de Castells (1998) se combinan los principios de subsidiariedad, 
flexibilidad, coordinación, participación ciudadana, transparencia administrativa, modernización tecnológica, transformación de los agentes y retroalimentación en la gestión.

\section{La encrucijada de los tiempos premodernos, modernos y postmoder- nos en Latinoamérica}

La complejidad de la realidad social de Latinoamérica contemporánea está quizás pensada como una complejidad híbrida de ideologías, prácticas y condiciones de la premodernidad, modernidad y postmodernidad. Se ha generalizado un creciente cuestionamiento a los valores de la modernidad, sus supuestos de progreso lineal y la tendencia a identificarse con valores eurocéntricos (Tucker 1992).

Desde este punto de vista alternativo, la modernización fue el venero ideológico del capitalismo occidental cuyas incursiones en el resto del mundo lo mantuvo en un permanente retrazo. Como un mecanismo económico, el capitalismo puede ser adoptado como un instrumento democratizador que posibilita legitimar un gobierno. Los límites de la legalidad no son los mismos de lo legítimo. El subdesarrollo de Latinoamérica no fue el pecado de una omisión de países en el margen de la industrialización moderna, sino activamente un proceso viejo en el cual los términos comerciales fueron arreglados en detrimento de los Estados débiles productores de bienes primarios (Portes, 1997). Como un mecanismo económico, el capitalismo puede ser adoptado como un instrumento democratizador que posibilita legitimar un gobierno. Los límites de la legalidad no son los mismos de lo legítimo.

De hecho, los problemas contemporáneos de la globalización, la expansión del capitalismo tardío o postmoderno, han agravado los más crónicos problemas como en el caso de la región latinoamericana. En las últimas dos décadas, casi cada aspecto mayor de la vida económica, política y social en Latinoamérica ha estado influido por la integración acelerada de la región en el sistema capitalista global. La economía global fragmenta las estructuras económicas, políticas y sociales centradas en el Estado-nación porque limitan y entorpecen sus procesos de generación y acumulación de capital para orientarlas al espacio supranacional.

El capitalismo corporativo, también denominado neocapitalismo o capitalismo tardío, se basa en un régimen de propiedad privada difusa propio de las grandes corporaciones que conjuntan recursos de muchos accionistas. El corporativismo financiero pertenece a este neocapitalismo. De hecho, los problemas contemporáneos de la globalización, la expansión del capitalismo tardío o postmoderno han agravado los más crónicos problemas como en el caso de la región latinoamericana. Ahora la existencia de las estructuras de los Estados nacionales son rehenes de los agentes del capitalismo global, porque sirve a sus intereses transnacionales. 
En la lógica de los procesos de globalización, los Estados latinoamericanos compiten por recibir los beneficios de la apertura comercial, la atracción de inversiones extranjeras y la transferencia de la propiedad mediante privatizaciones de las empresas públicas a las elites capitalistas locales que se convierten en intermediarios de las grandes corporaciones transnacionales. La ideología neoliberal se ha usado para justificar la estrategia de las políticas de reestructuración y ajuste económico seguidas en la mayor parte de los países latinoamericanos desde los ochenta. Las consecuencias de estas políticas tienen relación con los efectos de la recesión de las economías de los ochentas y noventas. Las crueles medidas de austeridad han sido adoptadas por la mayor parte de los gobiernos de la región a fin de reducir sus gastos en educación, salud y otros servicios sociales de tal forma que pueden servir a la combinación de deudas de los sectores privados y públicos de los diferentes países.

La crisis de los Estados Latinoamericanos se agudiza en la década de los noventa con la ruptura de las alianzas con los sectores populares para incorporarse a los procesos económicos y socioculturales articulados con la globalización, a costa de la desarticulación de las economías locales, dando como resultado la profundización de las características de una sociedad dualista: sectores socioeconómicos incrustados en la modernidad y los procesos de globalización, y sectores desarticulados con bajos niveles de competitividad y sin posibilidades de mejorar su desarrollo, condenados a una dependencia tecnológica, financiera, etc. A pesar de todo, como resultado de la implementación de programas de liberalización económica, la sociedad se polariza reflejando las contradicciones del capitalismo industrial, a tal punto que se convierte en una sociedad dual en la que unos tienen acceso a los beneficios de la era de la información, mientras otros son totalmente excluidos.

No menos importante entre estas predicciones fue la expectativa que los factores demográficos responderían a la modernización y que, en particular, las tasas de fertilidad declinarían. Los resultados recientes han invalidado estas expectativas. Las teorías de la modernización no predijeron bien otras consecuencias de estos procesos de difusión. La reacción a los errores predictivos al acercamiento de la modernización no surgieron primero de la sociología norteamericana sino de su contraparte latinoamericana fuertemente influenciada por la economía política marxista. El marxismo es un acercamiento dialéctico al desarrollo de la humanidad y un enfoque desde el materialismo histórico para señalar la lucha de clases que evoluciona del desarrollo capitalista a una sociedad socialista integrada por un sistema de producción, distribución y consumo formado por individuos iguales en un Estado democrático. Con estas raíces teóricas firmemente plantadas en la economía política marxista, los trabajos sobre la dependencia dejó de lado todas las consideraciones de valores e ideas y culpó de la pobreza del Tercer Mundo a las corporaciones multinacionales y sus gobiernos protectores. 
Los procesos de integración están acentuando las diferencias entre los espacios rurales y los urbanos y por lo mismo se reconfiguran las grandes urbes en megasuburbios que coexisten con «ciudades perdidas» o cinturones humanos de miseria en «asentamientos que escapan a las normas modernas de construcción urbana» (Galeano, 1971: 183), donde más de una cuarta parte de la población marginal latinoamericana habita. Los cambios en la geografía social rural entra en procesos de extinción en el siglo pasado que se manifiesta en el éxodo de una mayor parte de campesinos que abandonan el campo y su cosmovisión de la vida rural, quedando menos de un tres por ciento en las sociedades más avanzadas, para integrarse a las redes de la vida urbana postmoderna y postindustrial.

La distancia que separa a los agricultores entre el lugar de cultivo y el mercado es la que determina su marginalidad, y por lo tanto, el granero de la producción agropecuaria global se encuentra cerca de los grandes centros comerciales e industriales. Queda claro actualmente que el comercio internacional es más cuestión de poder político que de desarrollo, en donde los grandes intereses definen negociaciones y acuerdos. Las redes de poder atrapan a los ciudadanos y los someten a la lógica de una esfera de influencias y competencias con altos costos para quienes optan por alternativas diferentes que implican la negación de las telarañas de poder. Maximizar los beneficios y minimizar el impacto de los eventos negativos se ha convertido en un asunto colectivo. Los beneficios son mayores entre los países de altos ingresos, como los de la OCDE que entre los países pobres.

El territorio representa un conjunto de relaciones sociales, lugar donde la cultura y otros rasgos locales no transferibles se han sedimentado, donde los hombres y las empresas actúan y establecen relaciones, donde las instituciones públicas y privadas mediante su accionar intervienen para regular la sociedad (Camagni, 1991). Sin embargo, en la actualidad las relaciones sociales se están dislocando y descontextualizando de los procesos de interacción social. Boisier (2002) plantea la existencia de un conjunto de factores intangibles presentes y latentes en todo el territorio, que agrupadas en categorías homogéneas constituyen un capital intangible. De acuerdo con lo anterior, Dalton (2002) argumenta que en América Latina ha existido siempre una excesiva instrumentalización política de los marcos jurídicos de forma tal que no existe siempre una clara diferenciación y en la realidad lo que se presentaba era un subordinación a las luchas y estrategias políticas.

Una economía moderna en América Latina sólo es viable si se forma lo que Dietererich (2002) denomina el Bloque Regional de Poder, cuya diferencia cualitativa a los demás bloques de poder es que debe integrar desde su inicio elementos claves de la Democracia Participativa, o sea, del Socialismo del siglo XXI, con una política mercantilista y con sustento en cuatro polos de crecimiento:1. las pequeñas y medianas empresas (PYMES); 2. las corporaciones transnacionales nacionales $(\mathrm{CTN}) ; 3$. las cooperativas y, 4. las empresas e instituciones estratégicas del Estado. Esta verdad debería consti- 
tuir, por lo tanto, el punto de partida de toda teoría y planificación económica en América Latina.

\section{Conclusiones}

A partir del análisis de la modernidad y postmodernidad como formas de sustentabilidad social, bajo los supuestos de que los modernistas asumen que la función primaria de la organización económica es la producción, los postmodernistas asumen que la producción de cosas físicas es sobrepasada por la producción de bienes de información y servicios. Muchos de los habitantes de la regiones menos desarrolladas en Latinoamérica viven bajo condiciones que pueden ser descritas como modernidad desigual más que postmodernidad.

Para contrarrestar los efectos perversos de este desarrollo del capitalismo neoliberal se organizan los nuevos movimientos sociales capaces de combatir los poderes económico-financieros, que son los primeros signos del descubrimiento colectivo de la necesidad vital del internacionalismo o, mejor aún, de la internacionalización de los modos de pensamiento y de las formas de acción.

Finalmente se analiza la complejidad de la realidad económica y social como una encrucijada de los tiempos premodernos, modernos y postmodernos del desarrollo de Latinoamérica. Se concluye que el subdesarrollo de Latinoamérica no fue el pecado de una omisión de países en el margen de la industrialización moderna, sino activamente un proceso viejo en el cual los términos comerciales fueron arreglados en detrimento de los Estados débiles productores de bienes primarios.

De hecho, los procesos contemporáneos de la globalización y la expansión del capitalismo tardío o postmoderno han agravado los más crónicos problemas del desarrollo económico y social como en el caso de la región latinoamericana. Como conclusión, los procesos de la globalización benefician a los países con economías abiertas. Debe quedar abierta la posibilidad en el debate de que la obtención más rápida del incremento de la riqueza no es necesariamente el fin que la economía global debe perseguir.

\section{Bibliografía}

Amín, Samir (2001). Imperialismo y globalización (disponible en $<\mathrm{http}: / /$ www.rcci.net/globalización/2001/fg175.htm>).

Asenjo, J. (1984). «La constitución económica española». Centro de Estudios Constitucionales, Madrid.

AzIZ Chaudry, K. (1993). "The myths of the market and the common history of late Developers», Politics and Society, 21 (3, September 1993: 246). 
BARtlett, G. A. \& Ghoshal, S. (1998). Managing across borders: The transnational solution ( $2^{\text {nd }}$ edition), Boston: Harvard Business School Press.

Bauman, Zygmunt (1998). Globalization: The human consequences. Polity Press, Cambridge.

BIRCHFIELD, Vicki (1999). «Contesting the hegemony of market ideology: Gramsci's 'good sense' and Polanyi's 'double movement'. Review of International Political Economy, 6:1, Spring 1999: 27-54.

BoIsIER, S. (2002). Desarrollo territorial y descentralización. Seminario «Descentralización de sectores sociales; nudos críticos y alternativas». Lima, Perú, Abril 9 al 11.

BourdeAu, Pierre (1998). «The essence of neoliberalism», Le Monde. December.

Bourdieu, P. (1992). «Ökonomisches Kapital -Kulturelles Kapital -Soziales Kapital», en Schriften Zu Politic und Kultur: Die verborgenen Mechanism. Hamburg: VSA-Verlag.

Brosius, Peter (1997). «Endangered Forest, Endangered people: environmentalist representations of indigenous knowledge» en Human Ecology N. ${ }^{\circ}$ 25:1. pp. 47-69. s/1.

Camagni, R. (2001). «Cities: a case in point» en Steilmann, K. y Lehner F. (Eds.) The Steilmann Report. The Wealth of people-an intelligent economy for the $21^{\text {st }}$ century. Bochum-Wattensceind, KSI.

Cardozo, F.H. y Enzo Faletto (1969). Dependencia y Desarrollo en América Latina. Fondo de Cultura Económica. México.

CAstells, Manuel (1998). «¿Hacia el estado red? Globalización económica e instituciones políticas en la era de la información», en Seminário Internacional sobre Sociedade e Reforma do Estado. Brasilia: Mare.

DALton, Russell J. (2002) «Democracy and its citizens: Patterns of political change», Mimeo.

DiETERERICH, Steffan Heinz (2002). «Jaula de leones, economía de ovejas», La página de Dieterich, La nación, 10 de Agosto, Buenos Aires.

DowBoR, Ladislau (2001). «Descentralization and governance» (disponible en <http://www.ppbr.com/ld/govern.shtml>).

DroR, Yehezel (1995). «Fortalecimiento de la capacidad de los gobiernos en materia de formulación de políticas», Documento presentado a la 12 Reunión de expertos del Programa de las Naciones Unidas en materia de Administración y Finanzas Públicas, Nueva York, 31 de julio a 11 de agosto de 1995.

EsCOBAR, Arturo (2000). «El lugar de la naturaleza o la naturaleza del lugar globalización o postdesarrollo» en Viola, Andreu comp. Antropología del desarrollo. Teorías y estudios etnográficos en América Latina. Pp. 169216 Paidós studio. España.

FAGUET, J. (1999). «Does decentralization increase responsiveness to local needs? Evidence from Bolivia». Working Paper SN. World Bank Policy Research. 
FAZIO, Carlos (2000). «La solidaridad en los tiempos del neoliberalismo», La Jornada, Masiosare, página 12.

Galeano, Eduardo (1971). Las venas abiertas de América Latina. Madrid, Siglo XXI.

GARZÓN VALDÉS (1995). «Acerca del concepto de corrupción», Claves de la razón práctica, n. $^{\circ}$ 56, Octubre de 1995.

Germani, Gino (1971). Sociología de la modernización. Paidós. Buenos Aires.

GIDDENS (1990). The consequences of modernity. Stanford University Press.

GIDDENS, A. (1984). The constitution of society. Los Ángeles. University of California Press.

Gino, H. (1966). Política y sociedad en una época de transición. Buenos Aires: Piados.

GoulET, Denis (2000). «Changing development debates under globalization», Working paper \# 276. The Hellen Kellog Institute for International Studies.

GraHAm \& GiBSON (1996). The end of capitalism (as we knew it). Basil Blackwell. Oxford. G.B.

Grootaert, Christiaan (1998) «Social capital: the Missing Link?», Social Capital Initiative. Paper 3, World Bank, April, 1998.

Habermas, J. (1992). Between facts and norms. Cambridge, MA: The MIT Press. (Primera Edición en alemán, 1992).

LECHNER, Norbert (2000). «Desafíos en el desarrollo humano: individualización y capital social», Instituciones y Desarrollo, N. ${ }^{\circ} 7$, noviembre 2000.

LERNER, Daniel (1958) The passing of traditional society. Free Press.

McGRew, Anthony (1990). «A global society» in Stuart Hall, David Held, and Anthony McGrew, Modernity and its futures. Cambridge: Polity Press.

Morales-Gómez Daniel y TORRES, Mario (2000). «Re-thinking social policy for development», SDP Group. UNRISD Conference on social policy in a development context», 23-24 Sptiembre del 2002, Stockholm.

PORTES, Alejandro. (1997) «Neoliberalism and the sociology of development» Population and Development Review, Vol. 27, Numer 2, June 1997.

Putnam, R. (1993) Making democracy work: Civic traditions in Modern Italy. Princeton: Princeton University Press.

RAMíREZ Alujas, Álvaro Vicente (2002). Reforma del Estado y modernización de la gestión pública. Lecciones y aprendizajes de la experiencia chilena. Instituto Internacional de Gobernabilidad. 17 de septiembre

Rostow, W.W. (1960). The stages of economic growth: a non communist manifesto. Cambridge.

SLOTERDiJK, Peter (1999). «Patria y globalización», Nexos 262, Octubre.

SOKAL, Alan y BRICMONT Jean (1999). «La crítica al relativismo postmodernista», Este País, número 104, Noviembre. 
Tomlinson, John (1999). Globalization and culture. Polity Press: Cambridge.

TUCKER, Vince (1991). The myth of development. Occasional series paper $N^{\circ} 6$ Department of Sociology. University College. Cork.

WAGNER, Peter (1997). Sociología de la modernidad, Herder, 1997.

WALLERSTEIN, Immanuel (1997) «¿Cambio social? El cambio es eterno, nada cambia jamás». Memoria N. ${ }^{\circ}$ 100. P del cemos. México, junio 1997. 
